\title{
ARTICULAÇÃO ENTRE A COMPETÊNCIA EM INFORMAÇÃO, A GESTÃO DE PESSOAS E A APRENDIZAGEM ORGANIZACIONAL SIGNIFICATIVA: UMA REFLEXÃO SOBRE NOVAS CONDUTAS APLICÁVEIS ÀS BIBLIOTECAS PÚBLICAS
}

\author{
RELATIONSHIP BETWEEN INFORMATION LITERACY, \\ STAFF MANAGEMENT AND ORGANIZATIONAL \\ LEARNING: A REFLECTION AROUND PUBLIC \\ LIBRARIES
}

\author{
Rafaela Carolina da Silvab \\ Miriam Fernandes Jesusc \\ Vania Cristina Pastri Gutierrez ${ }^{d}$ \\ Regina Célia Baptista Belluzzo \\ Daniela Pereira Reis ${ }^{\dagger}$
}

a Este trabalho é resultado de seminário apresentado na disciplina "Gestão de pessoas, aprendizagem organizacional e competência em informação: novas condutas na sociedade contemporânea", ministrada pelas Profas. Dras. Regina Célia Baptista Belluzzo e Daniela Pereira dos Reis, do Programa de Pós-Graduação em Ciência da Informação da Universidade Estadual Paulista "Júlio de Mesquita Filho".

b Mestranda em Ciência da Informação pelo Programa de Pós-Graduação em Ciência da Informação da Universidade Estadual Paulista (PPGCI-UNESP). E-mail: rafaelacarolinasilva@gmail.com

c Mestranda em Ciência da Informação pelo Programa de Pós-Graduação em Ciência da Informação da Universidade Estadual Paulista (PPGCI-UNESP). E-mail: biblioteconomiriam@hotmail.com

d Doutoranda em Ciência da Informação pelo Programa de Pós-Graduação em Ciência da Informação da Universidade Estadual Paulista (PPGCI-UNESP). E-mail: vaniagutierrez@uol.com.br

e Doutora em Ciências da Comunicação pela Universidade de São Paulo (USP). Professora do Programa de Pós-Graduação em Ciência da Informação da Universidade Estadual Paulista (PPGCI-UNESP). E-mail: rbelluzzo@gmail.com

f Doutora em Ciência da Informação pela Universidade Estadual Paulista (UNESP). Professora do Departamento de Ciência da Informação da Universidade Estadual Paulista (UNESP). Email: danimatihe@gmail.com 


\section{RESUMO}

Introdução: os bibliotecários, esses gestores da informação, devem desenvolver a competência em informação ao entenderem que cada indivíduo é capaz de criar, adquirir e compartilhar conhecimento, o que impacta diretamente nos valores econômicos e sociais da organização onde se inserem, à medida que as instituições almejam profissionais mais competentes no gerenciamento e execução de seus processos e atividades. Logo, entende-se que a competência em informação é parte integrante dos modelos de gestão de pessoas e da aprendizagem organizacional. Objetivo: compreender a relação da competência em informação, da gestão de pessoas e da aprendizagem organizacional no auxílio à atuação profissional em bibliotecas públicas. Metodologia: trata-se de uma pesquisa bibliográfica e explicativa, que se utilizou de uma abordagem qualitativa, do tipo descritiva. Resultados: a gestão de pessoas para a aprendizagem significativa em bibliotecas públicas deve ir ao encontro do desenvolvimento de processos que promovam diferentes capacidades, que inclui: capacidade de reconhecer as necessidades de informação, de armazenar e recuperar a informação, de aplicar a informação para criar e comunicar conhecimento, de fazer uso eficaz e ético da informação e de localizar e avaliar a qualidade da informação. Conclusões: ao trabalhar com as capacidades interdisciplinares das três áreas destacadas por este estudo, os bibliotecários atuantes em bibliotecas públicas serão capazes de democratizar o acesso à informação, capacitando os usuários para o seu uso crítico, além de lhes proporcionar condições do exercício da cidadania.

Descritores: Competência em informação. Gestão de pessoas. Aprendizagem organizacional. Bibliotecas públicas.

\section{INTRODUÇÃO}

Levando-se em conta a competência como um conjunto de aprendizagens sociais e comunicacionais (LE BOTERF, 1995), pode-se entender que seus meios de aplicação são utilizáveis e necessários aos mais variados contextos, principalmente no que se refere à aprendizagem reflexiva e crítica. Schon (2000) discute a prática reflexiva ancorada nos conceitos de reflexão na ação, reflexão sobre a ação e reflexão sobre a reflexão na ação nas diferentes organizações, assim como bibliotecas públicas (BP), configurandose como mediadora de ensino e aprendizagem, uma vez que permite o pensar sobre o fazer orientando a ação. Considera-se, ainda, que a aprendizagem se dá quando o aprendente (re) constrói o conhecimento e forma conceitos significativos sobre o mundo, o que vai possibilitá-lo agir e reagir diante da realidade. Não há mais espaço para a repetição memorística, para a falta de contextualização e para a aprendizagem não significativa. Sem um propósito, 
qualquer aprendizagem é inócua. Desse modo, os ensinamentos de Paulo Freire convergem para transformar o processo de aquisição do conhecimento em uma aprendizagem significativa reflexiva e crítica, como destaca Moreira (2000), em que os ensinamentos fazem parte da cultura e que permitem ao homem lidar construtivamente com a mudança sem deixar-se dominar ou fragilizar-se por ela, adquirir a informação sem sentir-se impotente frente a sua grande disponibilidade e velocidade de fluxo. Logo, entende-se a competência, nesse cenário, como um modo adequado e inteligente de se buscar/utilizar a informação para se atingir um objetivo específico.

Destaca-se, ainda, que as BP atuam como mediadoras da informação entre diversas culturas e grupos sociais. Assim, possibilitam 0 compartilhamento da informação entre os diferentes colaboradores e seus usuários, por meio da aprendizagem organizacional significativa (AOS), trabalhando com a gestão de pessoas (GP) para a capacitação de habilidades profissionais e pessoais em prol do desenvolvimento humano. Considera-se a competência em informação (Colnfo) como parte integrante dos modelos de GP que tratam dos processos de solução de problemas e de tomada de decisão, por meio do uso inteligente da informação. Os bibliotecários, por serem gestores da informação, podem desenvolver a Colnfo, entendendo que cada indivíduo é capaz de criar, adquirir e compartilhar conhecimento, o que impacta nos valores institucionais econômicos e sociais. Ao destacar a Colnfo como um mecanismo de capacitação para o desenvolvimento da AOS, este estudo buscou entender como ela pode contribuir, por meio da gestão de pessoas, para as bibliotecas. O objetivo foi compreender a relação da Colnfo, da AOS e da GP para a atuação profissional em BP, apoiando-se em novas condutas importantes no contexto das demandas contemporâneas para 0 acesso e uso inteligente da informação. Esta proposta caracteriza-se por ser de natureza teórica e justifica-se devido à necessidade de melhoria dos serviços oferecidos pelas BP em relação à ampliação das possibilidades de acesso efetivo à informação pelos seus usuários, no que se refere à determinação da 
natureza e extensão da necessidade de informação, ao alcance de objetivos, à avaliação crítica da informação e suas fontes, e ao uso ético e legal da informação. Na metodologia, utilizou-se uma abordagem qualitativa, explicativa e do tipo descritiva (GIL, 2008), bem como o método de pesquisa bibliográfica, com o intuito de relacionar as temáticas: bibliotecas públicas, Colnfo, GP e AOS. As bases de dados Scientific Electronic Library Online (Scielo), Web of Science, Library Information Science Abstratcs (LISA), Base de Dados Referencial de Artigos de Periódicos em Ciência da Informação (BRAPCI), Portal de Periódicos da CAPES e Biblioteca Digital Brasileira de Teses e Dissertações (BDTD) foram escolhidas para coletar materiais bibliográficos para a leitura. Os critérios adotados para a seleção dos materiais delimitaram que os artigos se encontrassem completos e nos idiomas português (do Brasil ou de Portugal), inglês, espanhol ou francês, esses de conhecimento das autoras. A leitura do material foi feita no título, resumo, palavras-chave e resultados e discussões, de modo a compreender como o bibliotecário atuante em bibliotecas públicas pode vir a trabalhar com a GP, a AOS e a Colnfo no seu dia a dia.

\section{BIBLIOTECAS PÚBLICAS (BP)}

O objetivo central das BP deve ser a integração das comunidades nas quais essas organizações estão inseridas, estabelecendo sua interlocução com as esferas política, econômica, social, tecnológica e cultural. "[...] As pessoas, além de se tornarem leitoras, necessitam ser competentes para aprender por meio da informação" (CAMPELLO, 2009, p. 16). Dessa forma, busca-se demonstrar que tais instituições têm o compromisso de possibilitar a construção de uma sociedade democrática, proporcionando bases de formação para um indivíduo consciente, crítico e reflexivo, ou seja, competente em informação. Como destacam Barreto, Paradella e Assis (2008), as BP preocupam-se com o grau de imersão dos indivíduos nos processos geradores 
de informação e de conhecimento, buscando uma construção social. Esse contexto está em constante transformação em direção ao desenvolvimento da sociedade. Vale lembrar que, para Lessa e Gomes (2017), a BP, no Brasil e no mundo, passou por uma ressignificação referente ao seu conceito, estando sua função na projeção de seu ambiente físico como um local cultural híbrido, acessível, atrativo e confortável. Sintetizando Gomes (2014, p. 160), pode-se destacar as principais características da BP, a saber: 1) Postura de acolhimento - espaço educativo e cultural que acolhe e reconhece as diferenças e singularidades da comunidade; 2) Atitude de projeção - projeta a comunidade rumo ao conhecimento; 3) Fomentar a cooperação - local de fomento a parcerias, trocas e ações cooperativas; 4) Proporcionar e desenvolver sinergia - espaço de articulação de saberes; 5) Assumir comportamento pró-ativo quanto às políticas públicas - atuar pelo desenvolvimento de políticas voltadas ao protagonismo social e cultural; 6) Favorecer a formação, conservação e o acesso à memória coletiva - constituir e disponibilizar acervos diversificados; 7) Cultivar e estimular a dialogia - com função de local de interlocuções e trocas simbólicas; 8) Saber redesenhar-se redefinindo permanentemente suas práticas culturais e a atuação de seus profissionais como mediadores da informação; 9) Constituir-se como uma estação cultural - promovendo a produção e ressignificação dos saberes; 10) Atuar no foco da infoeducação - orientando e também educando para o mundo informacional.

Constituir uma BP implica "[...] em pensá-la como um espaço onde as pessoas são estimuladas à participação cidadã, onde são convocadas a formar opinião pública e discutir possíveis mudanças sociais [...]" (LESSA; GOMES, 2017, p. 43). Essas autoras indicam que a BP deve perceber as novas demandas sociais e estabelecer condutas de gestão que permitam inovar e incorporar serviços e produtos que motivem os usuários e sua capacidade cultural, o que implica no desenvolvimento de competências e habilidades no novo cenário social. É condição sine qua non destacar que a atuação da BP se 
solidifica sob a responsabilidade de um profissional capacitado para promover ações que possibilitem atingir seus objetivos. Deve-se estar preparado para realizar atividades que sejam significativas e consigam aperfeiçoar a forma pela qual as pessoas se apropriam de informações políticas, culturais, ambientais, econômicas, tecnológicas, entre outras. A BP é "[...] um organismo que converge seus objetivos em favor do usuário, para suas necessidades e particularidades de informação" (BERNARDINO; SUAIDEN, 2011, p. 34-35), logo, é uma célula viva, que se destaca socialmente, pois, suas políticas refletem a missão da instituição perante a comunidade na qual está inserida, a fim de oferecer acesso à informação para todos, democratizando a informação e formando cidadãos conscientes. Devem procurar: 1) Oferecer acesso ao conhecimento humano, independentemente da forma de registro; 2) Fazer parte de uma rede mundial de bibliotecas; 3) Oportunidades de formação e aprendizagem abertas; 4) Um espaço físico, possibilitando compartilhamentos e oportunidades de encontros; 5) Cooperação com outras instituições em especial as escolas e empresas; 6) Oferecer serviços especiais a grupos de interesse identificados junto à comunidade. Nessa perspectiva, compreende-se que a BP proporciona o contato com e entre as pessoas, além do acesso à informação, sendo um lugar em que os indivíduos, profissionais e usuários, podem reunir seus próprios pensamentos e interagir, por meio da apropriação de novas informações significativas, para a construção, a desconstrução e o compartilhamento de conhecimentos, sendo que a gestão de pessoas permite a interação entre o ambiente institucional, a AOS, a geração e a troca de conhecimentos, em prol de tornar os profissionais cada vez mais competentes em informação. Desenvolvem-se, assim, suas capacidades e habilidades, no emprego de ações inteligentes, para o atendimento e a identificação das necessidades de busca e uso da informação assertiva e efetiva por parte dos usuários. O intuito é sanar tais necessidades, estimulando e fidelizando retorno e a indicação dos serviços prestados pelos profissionais das BP aos seus usuários, o que propicia a divulgação dos serviços oferecidos para o rol de 
pessoas com quem esses indivíduos se relacionam, destacando-se 0 desenvolvimento de competências essenciais, dentre elas a Colnfo.

\section{COMPETÊNCIA EM INFORMAÇÃO (COINFO)}

A informação e o conhecimento são inseridos, atualmente, nas organizações como abordagens capazes de melhorar os resultados institucionais, por meio da GP e da AOS. Assim, a Colnfo pode ser utilizada como ferramenta estratégica para o alcance desse objetivo, buscando "[...] desenvolver, aprimorar e gerenciar capacidades, competências, habilidades e atitudes que tornam os indivíduos capazes de aplicar a informação na prática para compreender fenômenos, atualizar saberes, resolver problemas e tomar decisões" (SANTOS, 2017, p. 19). Portanto, entende-se que a Colnfo contribui para gerar conhecimento nos campos pessoal, educacional e profissional. A Colnfo surge em meados de 1970, quando o bibliotecário Paul Zurkowski, Presidente da Information Industries Association, elabora o relatório "The information service environment relationships and priorities", buscando traçar diretrizes para acompanhar o seguimento informacional do ambiente organizacional de que participava. Santos (2014) destaca que a Colnfo surgiu em meio ao crescimento informacional, ao uso de tecnologias e à necessidade de busca de soluções, utilizando-se, para tanto, de habilidades e competências dos usuários para acessarem e usarem, de maneira efetiva, as informações disponibilizadas. Na década de 1980, as habilidades e o conhecimento voltados à tecnologia da informação migram do ambiente bibliotecário para serem compartilhados e ensinados nas escolas secundárias, a fim de capacitar os estudantes no contexto escolar. Em 1990, a American Library Association (ALA) apontou que os usuários da informação deveriam ser aprendizes independentes, sendo que os profissionais da informação/bibliotecários teriam o papel de proporcionar, a esses usuários, rapidez e simplificação no acesso às informações (SANTOS, 2014). Nesse contexto, o gerenciamento do 
conhecimento e a Colnfo contribuem para o desenvolvimento de processos, atividades e na tomada de decisões. Catts e Lau (2008) destacam que, para lidarem com as situações de trabalho, os profissionais precisam utilizar a Colnfo de forma prática na compreensão de fatos, a fim de obterem êxito em futuras decisões.

De acordo com a ALA (1989), um indivíduo é competente em informação quando se torna capaz de reconhecer a importância da informação, possuindo habilidade para localizá-la, avaliá-la e usá-la efetivamente. Belluzzo (2010, p. 38) entende que a Colnfo se constitui em processo contínuo de "[...] interação e internalização de fundamentos conceituais, atitudinais e de habilidades específicas como referenciais à compreensão da informação e de sua abrangência, em busca da fluência e das capacidades necessárias à geração do conhecimento novo", em vista da sua aplicabilidade, ao longo da vida, ao cotidiano das pessoas e das comunidades. Assim, a Colnfo, segundo Belluzzo, Kobayashi e Feres (2004, p. 87), pode ser conceituada como o "[...] conjunto de comportamentos, habilidades e ações que envolvem o acesso e uso da informação de forma inteligente, tendo em vista a necessidade da construção do conhecimento e a intervenção na realidade social". Meneses Placeres (2008, p. 3, tradução nossa), aponta que a Colnfo é uma prática profissional correspondente às demandas socioculturais das sociedades complexas, essas caracterizadas pela relação entre os discursos informacionais e o funcionamento das sociedades no que se refere ao seu crescimento econômico, à mudança social, à expansão das tecnologias, dentre outros. Trata-se de um cenário de mudanças em que os recursos informacionais precisam "[...] ser aplicados às situações de trabalho, na resolução de problemas, por meio do aprendizado de técnicas e habilidades no uso de ferramentas de acesso à informação (DUDZIAK, 2001, p. 24). Como corrobora Yafushi (2015, p. 205-206), a Colnfo está relacionada ao saber "[...] como acessar, diagnosticar, usar, recuperar, tratar, reter, descartar, interpretar e gerenciar as informações, não só por meio de bases de dados disponibilizados 
na internet, mas também das bases humanas, compartilhando e trocando conhecimento". Portanto, a troca de informações e a futura criação de conhecimento entre os usuários/colaboradores das instituições, quando atreladas à prática profissional, resultam em tomada de decisões mais críticas e assertivas. Isto posto, a Colnfo é uma capacidade necessária aos cidadãos para se adaptarem ao contexto de globalização, instruindo as pessoas a entenderem suas necessidades informacionais, além da localização, seleção, interpretação e utilização de informações de maneira crítica e responsável (CAMPELLO, 2009). Nesse sentido, no atual contexto social, infere-se que a Colnfo contribui para a capacitação profissional, ao possibilitar que os indivíduos desenvolvam suas habilidades de necessidade, busca e uso eficiente da informação. Assim, a Colnfo surge como "fator crítico para produzir significado ao tratar o volume de dados e informações que são disponibilizados hoje e, acima de tudo, com a necessidade de produzir significado verdadeiro" (BELLUZZO; FERES, 2013, p. 9), o que resulta em profissionais cada vez mais capacitados e competentes, empenhados na busca pelo desenvolvimento de suas habilidades. Tais habilidades são transformadas em conhecimento explícito e aplicadas no processo de construção do conhecimento individual e corporativo, bem como na implementação de ações estratégicas organizacionais, havendo a necessidade de se salientar a importância da área de GP para tanto.

\section{GESTÃO DE PESSOAS (GP)}

Nas organizações, as pessoas vêm se aperfeiçoando ao longo dos anos para aumentar sua competitividade e se manter no mundo de trabalho. Durante a década de 1980, muito se falou sobre novas formas de GP, repensando conceitos que pudessem transformar os setores e as ações de uma organização. Entretanto, somente nos anos 1990 pôde-se contemplar "[...] propostas mais concretas de mudança [...] em novas formas de gerir pessoas" 
(FISCHER, et al., 2008, p. 31-32), formas essas que apresentaram resultados verdadeiramente positivos. Esses conceitos, na prática, permitem que as organizações sobrevivam e assegurem sua adequação para lidarem com a competitividade. Vale lembrar que, segundo Chiavenato (2008), a área de GP está em constante transformação, indo além da ideia de que as pessoas, mediante um contrato formal de trabalho, somente forneçam mão de obra simples, migrando para a oferta de conhecimento e competências, através de parcerias e colaboração, em especial, em uma economia informacional em que existe um excesso de informações e poucos indivíduos têm a capacidade de delinear o que realmente importa. Além disso, os avanços tecnológicos e a rapidez com que as informações transitam no mundo de hoje exigem da equipe uma dinâmica peculiar, fazendo-se necessário a ágil absorção desses dados, incorporando-os na realidade organizacional para que sejam utilizados a favor dos objetivos prédefinidos. Para realizar a GP em uma organização é preciso conhecer a missão e os objetivos pelos quais toda a equipe trabalha, realizando as adequações necessárias para manter o entusiasmo individual e coletivo de todos os colaboradores. Assim como um maestro que identifica potencialidades em uma orquestra e busca desenvolvê-las, um bom gestor de pessoas é responsável por gerenciar as pessoas que fazem parte de uma organização, devendo estar em total sintonia com sua equipe, visto que "[...] cada pessoa contribui com talento, habilidades e competências pessoais para a organização" (CHIAVENATO, 2010, p. 33). Estabelecer metas e prazos é indispensável para que todos tenham foco e desempenhem suas atribuições de forma positiva e saudável, salientando-se que devem estar alinhados à capacidade de trabalho dos colaboradores. A GP busca, atualmente, valorizar indicadores que fortaleçam uma organização, são eles, "[...] competências fundamentais, gestão de pessoas, mudanças na estrutura organizacional, inovação [e] custo de produção" (GRAMIGNA, 2007, p. 5). Dentre as diversas estratégias que têm ganhado destaque na GP, é possível citar a Colnfo, que deve ser reconhecida como requisito desde a formação básica/inicial à 
formação contínua das pessoas a fim de que possam ser reflexivas e investigativas e interajam verdadeiramente com os ambientes de expressão e construção do conhecimento, propondo mudanças significativas nas organizações.

Em se tratando de BP, encontram-se as afirmações de Cavalcante e Rasteli (2013, p. 157), que identificaram o bibliotecário como sendo "[...] agente socializador da informação", contribuindo no "[...] processo de aprendizagem dos indivíduos através das mais diversas formas de leituras e suportes, como também em suas práticas, ajudando o leitor a atingir nível elevado de complexidade no processo de leitura/escrita e na produção de sentido". Assim, ela pode ser empregada em favor dessas instituições com bons resultados em curto, médio e longo prazos. Os profissionais que têm a oportunidade de aprimorar seus conhecimentos e utilizá-los em prol das organizações que atuam conseguem atender as novas exigências do mundo de trabalho. Cativo, Cativo e Souza (2017), fazendo menção às competências demandadas por bibliotecários na gestão de bibliotecas, argumentam que esses profissionais são gestores e mediadores da informação, que planejam e executam ações a fim de interagir com o público e fazê-los enxergar para além das suas necessidades informacionais, sendo criativos, empreendedores e capazes de lidarem com sua equipe de trabalho, em prol de difundirem a aprendizagem e 0 conhecimento. Para melhor ilustrar as diferenças de um profissional que é gerido com conceitos de Colnfo, Gramigna (2007, p. 8) lista os sete motivos pelos quais uma instituição deve investir nas pessoas: 1) sem elas, qualquer tecnologia, por mais necessária e inovadora que seja, não funciona; 2) têm o dom de fazer o sucesso ou o fracasso de qualquer empresa; 3 ) trazem histórias de vida, emoções, saberes, valores, crenças e expectativas; 4) têm necessidade de integrar seus sonhos a um projeto coletivo; 5) carregam a expectativa de patrocínio desse empreendimento, no qual cada parte precisa ser atendida e o resultado deve ser favorável, do tipo ganha-ganha; 6) podem colocar seu talento a favor das organizações quanto encontram ambiente para 
tal; e 7) são leais àqueles que as respeitam, abrem oportunidades e as valorizam. Sendo assim, a GP perpassa por todos os setores de uma organização, estando muito além do simples contratar alguém, mas, atuando na capacitação e no desenvolvimento das habilidades dos colaboradores, identificando competências e estabelecendo confiança recíproca, levantando e identificando os pontos fortes e fracos, nivelando e norteando ações para que estes membros organizacionais se sintam cada vez mais valorizados, motivados e com ambiente adequado para a execução das suas tarefas e atividades. Logo, essas novas condutas de GP são aplicáveis às BP e aos profissionais que nela atuam, propiciando a realização de um conjunto de ações que visam consolidar e agregar os métodos de trabalho utilizados, bem como captar suas reais necessidades, resultando em sucessos individuais, profissionais e organizacionais. Para tanto, faz-se necessária a existência de uma área de grande importância, que se constitui como AOS.

\section{APRENDIZAGEM ORGANIZACIONAL SIGNIFICATIVA (AOS)}

A AOS é um campo multidisciplinar do conhecimento, que abrange a cultura e o desenvolvimento organizacional, a psicologia, a administração, a sociologia, as teorias organizacionais, dentre outras áreas, a fim de tornar a instituição que aprende em uma construção social capaz de transformar o conhecimento individual em ações institucionalizadas, com foco nos objetivos organizacionais (ANGELONI; STEIL, 2011). Dessa maneira, a AOS visa alcançar novos conhecimentos, formais e informais, passíveis de serem atribuídos no cotidiano da organização. Essa aprendizagem é definida como um processo dinâmico de criação, aquisição e integração de conhecimentos, visando ao desenvolvimento de capacidades e de recursos que contribuirão, posteriormente, para o melhor desempenho organizacional (LOPEZ; PEÓN; ORDÁZ, 2005). A AOS relaciona-se com a gestão do conhecimento, pois, trabalha com a instituição e com os indivíduos que a compõem, desenvolvendo 
competências em um determinado campo do conhecimento, além de destacar que todo tipo de organização tem potencial de aprendizagem (REZENDE, 2015). Nesse caso, entende-se que a BP, é passível de desenvolver aprendizado. A AOS pode ser entendida como uma escola de pensamento sobre as organizações (VERSIANI; FISCHER, 2008), isto é, um campo de estudo específico dos estudos organizacionais.

Para Caprioli e Araújo (2016), a AOS se configura como um processo de detecção e de correção de erros, ou seja, como um meio de aprimoramento das ações organizacionais, que só é alcançado quando se têm um maior conhecimento e compreensão dessas ações.

Segundo Antonello (2005), a AOS trabalha com seis focos: mudança, socialização da aprendizagem individual, processo-sistema, cultura, gerenciamento do conhecimento, melhoria contínua e inovação. Dentre esses focos, destacam-se cinco diferentes abordagens: aprendizagem como um processo, resultado ou produto; ênfase em um ou vários níveis de análise de aprendizagem, englobando, ao mesmo tempo, o indivíduo, o grupo e as relações entre organizações; abordagens descritivas envolvendo processos da AOS; aprendizagem prescritiva relativa aos resultados da organização que aprende, por meio da informação e do conhecimento; e, processos de aprendizagem como uma mudança cognitiva e comportamental. Ausubel (2003) trata especificamente da AOS, ampliando os focos de Antonello (2005) para outras dimensões de aprendizagem, ao destacar as experiências prévias do indivíduo na assimilação do conhecimento novo. As dimensões são: a) conteúdo potencialmente significativo e b) atitude favorável para aprender significativamente, o que requer do sujeito uma postura proativa no uso de seus esquemas de conhecimento, a fim de desenvolver a aprendizagem efetiva no contexto de uma organização. Nesse sentido, Moreira (2000) estende esse conceito para o que denomina de AOS crítica, como uma perspectiva que permite ao sujeito fazer parte de uma cultura, mas, reconhecer quando a realidade não está mais sendo captada pelo seu grupo, existindo alguns 
princípios que têm importância para o desenvolvimento dessas abordagens de cunho significativo, que, em síntese compreendem: 1) Conhecimento prévio. Aprendemos a partir do que já sabemos - Para ser crítico de algum conhecimento, de algum conceito, de algum enunciado, primeiramente o sujeito tem que aprendê-lo significativamente e, para isso, seu conhecimento prévio é, isoladamente, a variável mais importante; 2) Interação social e questionamento. Ensinar/aprender perguntas ao invés de respostas. $\mathrm{A}$ interação social é indispensável para a concretização do ensino; 3) Não centralidade de recursos únicos e diversidade de materiais instrucionais - A educação para a diversidade é uma das narrativas defendidas para a facilitação da aprendizagem; 4) $O$ aprendiz como perceptor/representador Diz respeito à aprendizagem receptiva, i.e., aquela em que o novo conhecimento é recebido pelo aprendiz, sem necessidade de descobri-lo, sendo o mecanismo humano para assimilar (reconstruir internamente) a informação; 5) $O$ conhecimento como linguagem - A linguagem não é neutra no processo de perceber e de avaliar nossas percepções, estando implicada em qualquer tentativa de percepção da realidade; 6) Consciência semântica Sejam quais forem os significados que tenham as palavras, eles foram atribuídos por pessoas a partir de suas experiências; 7) Aprendizagem pelo erro - O conhecimento humano é limitado e construído através da superação do erro; 8) Desaprendizagem - Desaprender aqui tem o significado de não usar o conhecimento prévio que impede que o sujeito capte os significados compartilhados sobre o novo conhecimento; 9) Incerteza do conhecimento Este princípio é, de certa forma, síntese dos anteriores, em particular daqueles que têm a ver com a linguagem. Assim, definições, perguntas e metáforas são três elementos com os quais a linguagem humana constrói uma visão de mundo. Esses conceitos e princípios que congregam a AOS devem fazer parte integrante de qualquer aprendizagem em ambiente de trabalho contemporâneo.

Janiunaite, Petraite e Cibulskas (2011), explicam que a aprendizagem 
somente ocorre quando as organizações promovem condições favoráveis para o seu desenvolvimento, destacando as experiências profissional e cultural, conjuntamente, a fim se conhecer o ambiente organizacional além das possibilidades de aprendizagem constante (ao longo da vida), que vão ao encontro das diretrizes da Colnfo em organizações. Busca-se a criação de conjuntos de rotinas e regras a serem criados e disseminados para que os indivíduos possam reconhecer a si mesmos nessas instituições. Em decorrência, percebe-se a necessidade de preparação das pessoas que atuam na organização, a fim de se gerenciar o excesso de informação circulante nesses ambientes. Logo, a informação passa a ser entendida como um insumo para a competitividade, já que permite a construção do conhecimento colaborativo, sendo possível converter práticas informacionais individuais em atividades incorporadas à cultura da organização. Destarte, para que a AOS aconteça efetivamente, é preciso considerar suas dimensões. São elas: clareza de propósito e missão; comprometimento da liderança e delegação de poder; experimentação para a aprendizagem; transferência de conhecimento e equipe de trabalho e solução de problemas (GOH; RICHARDS, 1997). Tais dimensões indicam que é por meio de uma ação que o indivíduo passa a refletir e, em uma etapa posterior, age novamente em um meio ambiente, sendo importante 0 compartilhamento da informação, identificado no comprometimento da liderança e na delegação de poder, pois, quanto melhor forem distribuídas as informações, maiores serão os conhecimentos sobre os processos internos da organização, o que tornará as ações mais assertivas. O mesmo acontece na experimentação para a aprendizagem e na transferência de conhecimento, em que há aprendizagem prática e ativa no uso do conhecimento recebido e no desenvolvimento das atividades. Quanto à equipe de trabalho e a solução de problemas relacionam-se à aprendizagem sistêmica, ou seja, o conhecimento do todo da organização por todos os indivíduos, de modo que as tomadas de decisões sejam estratégicas, mesmo em situações imprevistas pela instituição. Trata-se do conhecimento de processos, produtos e serviços em prol da 
adaptação do individual ao coletivo. Nesse contexto, destacam-se De Lucca, Fialho e Vitorino (2018) ao mencionar que, no cenário das organizações, a Colnfo caracteriza-se por ser uma estratégia de gestão do conhecimento, uma vez que cria um ambiente favorável à AOS. Dentre as modalidades de AOS, ressalta-se o processo de aprendizagem ao longo da vida, realizado por meio de cursos de curta duração, workshops e cursos de especialização; as práticas educativas, ou seja, a educação, em serviço, para o interesse organizacional; as capacitações em tempos específicos; e a educação permanente, colocando em pauta as práticas cotidianas como meios que auxiliam na formação de um profissional reflexivo. Tais modalidades trabalham métodos de domínio pessoal (alto grau de proficiência e capacidade de produzir resultados desejados), modelos mentais (ideias, generalizações, ou mesmo imagens que influenciam a visão de mundo e atitudes das pessoas) visão compartilhada (objetivos comuns com o foco e a energia para o aprendizado), aprendizagem em equipe (processo de alinhamento e desenvolvimento da capacidade de um grupo de criar resultados que deseja alcançar) e raciocínio sistêmico (apoiado em feedback com concepção de influência recíproca) (SENGE, 2004). Ressalta-se que as BP, para se tornarem "organizações que aprendem" e que se integram nos processos, não nascem prontas, bem ao contrário, isto acontece com o tempo, quando as pessoas vão entendendo os seus papéis. São condutas de GP que requerem uma ressignificação na sociedade e que precisam ser adotadas nas BP e na formação contínua dos bibliotecários que nelas se acham inseridos profissionalmente.

\section{METODOLOGIA}

$\mathrm{Na}$ condição de pesquisa de natureza teórica, este estudo objetivou analisar Colnfo como ferramenta estratégica na GP para a construção da BP como promotora da aprendizagem. Utilizou-se uma abordagem qualitativa, do tipo descritiva (GIL, 2008), e o método de pesquisa bibliográfico, com o intuito 
de relacionar as temáticas: BP, Colnfo, GP e AOS. O levantamento dos dados iniciou-se com a análise dos conceitos de Colnfo e de AOS, reflexiva e crítica nos processos de GP em BP. As referências utilizadas acham-se em bases de dados da área da Ciência da Informação, tais como: Scielo e Web of Science, LISA, BRAPCI, Portal de Periódicos da CAPES e BDTD, destacando-se autores de referência para a área. Em um segundo momento, foi explorada a relação existente entre as BP, a gestão de pessoas, a AOS e a Colnfo, no que diz respeito à atuação do bibliotecário. Para tanto, utilizou-se o framework de inserção e desenvolvimento da Colnfo em nível institucional desenvolvido por Santos (2017), buscando a institucionalização da mesma nas BP. As abordagens de GP utilizadas foram de Dutra (2004) e de Chiavenato (2008) e para a Colnfo, os padrões e indicadores de Colnfo propostos por Belluzzo (2007) e o framework de Santos (2017). Já para a AOS foram as abordagens de Moreira (2000), Ausubel (2003) e Antonello (2005). Por fim, observou-se como essa relação impacta no campo científico da Ciência da Informação e nas necessidades prementes para a prática profissional nesses ambientes informacionais.

\section{ANÁLISE E DISCUSSÃO DOS RESULTADOS}

O papel da Colnfo, e também das BP, está relacionado ao seu uso estratégico para o exercício da cidadania, o que implica em recursos cognitivos e no compartilhamento humano da informação. Nessa perspectiva, o mapeamento da Colnfo torna-se necessário para que se implementem Programas de Colnfo, bem como para o desenvolvimento de GP, com foco na AOS, reflexiva e crítica a fim de se conhecer as reais necessidades informacionais da comunidade com quem se pretende trabalhar e, assim, desenvolver a aprendizagem dos profissionais que lá atuam, de modo que eles trabalhem em prol de serviços e produtos que instiguem a reflexão de seus usuários acerca da cidadania. No contexto deste estudo, três questões foram 
Rafaela Carolina da Silva, Miriam Fernandes Jesus, Vania Cristina Pastri Gutierrez, Regina Célia Baptista Belluzzo, Daniela Pereira Reis

Articulação entre a competência em informação, a gestão de pessoas e a aprendizagem organizacional significativa: uma reflexão sobre novas condutas aplicáveis às bibliotecas públicas

levantadas: "Como os padrões e indicadores de Colnfo se correlacionam com a gestão de pessoas?", "Como os padrões e indicadores de Colnfo podem se relacionar com a AOS?" e "Como a institucionalização da Colnfo, da GP e da AOS poderá contribuir para a atuação profissional em BP?". Nessa perspectiva, desenvolveu-se o Quadro 1 que, a partir das pesquisas de Santos (2017), Belluzzo (2007), Dutra (2004), Chiavenato (2008), Ausubel (2003), Moreira (2000) e Antonello (2005), propõe a Colnfo como estratégia na GP para a AOS reflexiva e crítica em $\mathrm{BP}$.

\section{Quadro 1 - Aplicação do Framework da Colnfo' como estratégia na GP para a AOS reflexiva e crítica em BP}

\begin{tabular}{|c|c|}
\hline \multicolumn{2}{|r|}{ Colnfo, GP e AO institucionalizada na BP } \\
\hline Ideia central & $\begin{array}{l}\text { O objetivo central das BP deve ir de encontro à ação de integrar as } \\
\text { comunidades nas quais essas organizações estão inseridas, estabelecendo } \\
\text { sua interlocução com as esferas política, econômica, social, tecnológica e } \\
\text { cultural. Como destacam Barreto, Paradella e Assis (2008), as BP preocupam- } \\
\text { se com o grau de imersão dos indivíduos nos processos geradores de } \\
\text { informação e de conhecimento, buscando uma construção social. Campello } \\
\text { (2009, p. 19, grifo nosso) afirma que cabe ao bibliotecário "[...] democratizar a a } \\
\text { acesso à informação, capacitar as pessoas para o uso crítico da informação, } \\
\text { proporcionar condições que permitam a reflexão, a crítica e a construção de } \\
\text { ideias por meio da leitura". }\end{array}$ \\
\hline Marcos gerais & $\begin{array}{l}\text { Padrão } 1 \text { - A pessoa competente em informação determina a natureza e a } \\
\text { extensão da necessidade de informação.; Padrão } 2 \text { - A pessoa competente } \\
\text { em informação acessa a informação necessária com efetividade; Padrão } 3-A \\
\text { pessoa competente em informação avalia criticamente a informação e as suas } \\
\text { fontes; Padrão } 4 \text { - A pessoa competente em informação, individualmente ou } \\
\text { como membro de um grupo, usa a informação com efetividade para alcançar } \\
\text { um objetivo/obter um resultado; Padrão } 5 \text { - A pessoa competente em } \\
\text { informação compreende as questões econômicas, legais e sociais da } \\
\text { ambiência do uso da informação e acessa e usa a informação ética e } \\
\text { legalmente. }{ }^{2}\end{array}$ \\
\hline $\begin{array}{l}\text { Linhas de } \\
\text { ação }\end{array}$ & $\begin{array}{l}\text { Abordagens da Gestão de } \text { Pessoas }^{3} \text { : Provisão de pessoas necessárias } \\
\text { adequadas; Aplicação de pessoas aos seus cargos e funções; Manutenção de } \\
\text { pessoas, dotando-as de competências; Liderança e acompanhamento de } \\
\text { pessoas; Avaliação e reavaliação de processos, métodos e competências } \\
\text { efetivas necessárias. } \\
\text { Abordagens da AOS reflexiva e crítica4: Aprendizagem como um processo, } \\
\text { resultado ou produto; Ênfase em um ou vários níveis de análise de }\end{array}$ \\
\hline \multicolumn{2}{|c|}{$\begin{array}{l}2 \text { Padrões e indicadores de Colnfo da ALA/Information Literacy Competency Standards for } \\
\text { Higher Education da Association of College and Research Libraries (ACRL) (2000), em } \\
\text { conjunto com os de Belluzzo (2007). }\end{array}$} \\
\hline \multicolumn{2}{|c|}{${ }^{3}$ Dutra (2004); Chiavenato (2008). } \\
\hline & \\
\hline
\end{tabular}


Rafaela Carolina da Silva, Miriam Fernandes Jesus, Vania Cristina Pastri Gutierrez, Regina Célia Baptista Belluzzo, Daniela Pereira Reis

Articulação entre a competência em informação, a gestão de pessoas e a aprendizagem organizacional significativa: uma reflexão sobre novas condutas aplicáveis às bibliotecas públicas

\begin{tabular}{|l|l|}
\hline \multirow{5}{*}{$\begin{array}{l}\text { Resultados } \\
\text { desejáveis }\end{array}$} & $\begin{array}{l}\text { aprendizagem, englobando, ao mesmo tempo, o indivíduo, o grupo e as } \\
\text { relações entre organizações / atitude favorável para aprender } \\
\text { significativamente; Abordagens descritivas, com foco nos processos da AOS; } \\
\text { Aprendizagem prescritiva, com foco nos resultados da organização que } \\
\text { aprende, por meio da informação e do conhecimento; Processos de } \\
\text { aprendizagem como uma mudança cognitiva e comportamental / conteúdo } \\
\text { potencialmente significativo. }\end{array}$ \\
\hline $\begin{array}{l}\text { Capacidade de reconhecer as necessidades de informação: identificação das } \\
\text { informaçães necessárias para a solução de problemas } \\
\text { individuais/organizacionais; Capacidade de armazenar e recuperar } \\
\text { informação: gestão eficiente da informação e uso inteligente de ferramentas } \\
\text { tecnológicas, seleção, tratamento, disseminação, descarte e recuperação da } \\
\text { informação para seu uso assertivo; Capacidade de aplicar a informação para } \\
\text { criar e comunicar conhecimento: institucionalização da informação tratada no } \\
\text { item anterior, com base nos conhecimentos implícitos e explícitos; ressalta-se } \\
\text { que o conhecimento implícito, quando disseminado, torna-se explícito, por } \\
\text { meio de fluxos de informação, normas e procedimentos implementados; } \\
\text { Capacidade de fazer uso eficaz e ético da informação: utilizar a informação } \\
\text { corretamente com base em uma postura ética e legal, seguindo normas } \\
\text { sociais e legislação vigente; Capacidade de localizar e avaliar a qualidade da } \\
\text { informação: uso de fontes de informação seguras, avaliação da veracidade da } \\
\text { informação e da sua qualidade no âmbito inovador, agregando-a e aplicando- } \\
\text { a, de maneira estratégica, na performance informacional do usuário. }\end{array}$ \\
\hline
\end{tabular}

Fonte: Elaborado pelas autoras.

O Quadro 1 foi elaborado de acordo com a ideia de framework de Santos (2017), sendo uma fundamentação teórica de ideias, metas e linhas de ação para o desenvolvimento, institucionalizado, da Colnfo em BP. A "ideia central" se refere à contextualização dos cenários e conceitos aos quais a Colnfo será implantada, nesse caso, nas BP. Os "marcos gerais" demonstram a disponibilização geral de como será feita a implementação da Colnfo na instituição. Aqui, foram utilizados os cinco indicadores e padrões de Colnfo propostos pela ALA, ACRL (2000), em conjunto com os de Belluzzo (2007), a saber: Padrão 1 - trabalha com a determinação da natureza e da extensão da necessidade de informação; Padrão 2 - refere-se ao acesso à informação necessária com efetividade; Padrão 3 - destaca a avaliação crítica da informação e das suas fontes; Padrão 4 - ocupa-se do uso da informação com efetividade para alcançar um objetivo ou obter um resultado e Padrão 5 compreende as questões econômicas, legais e sociais da ambiência do uso da informação, bem como do seu acesso e uso ético e legal. Em "linhas de ação", o framework busca aplicar a operacionalização proposta nos "marcos gerais". 
Dessa maneira, o estudo utilizou-se de macro abordagens - 1) GP (DUTRA, 2004; CHIAVENATO, 2008) e 2) AOS (MOREIRA, 2000; AUSUBEL, 2003; ANTONELLO, 2005). As abordagens da GP de Dutra (2004) e de Chiavenato (2008) englobam cinco perspectivas. A saber: a) provisão de pessoas necessárias e adequadas (processos de inclusão de pessoas na organização, com início no planejamento de recursos humanos, perpassando pelas pesquisas de mercado e finalizando nos processos de recrutamento, seleção e integração de pessoas); b) aplicação de pessoas aos seus cargos e funções (processos que delineiam as atividades que as pessoas irão realizar na organização, em vistas de orientar e acompanhar o seu desempenho: desenho organizacional, desenho de cargos, análise e descrição de cargos, planejamento e alocação de recursos humanos, plano de carreiras, orientação às pessoas, avaliação do desempenho e disseminação da cultura organizacional); c) manutenção de pessoas, dotando-as de competências (processos de capacitação, desenvolvimento profissional e pessoal, a partir da criação de condições ambientais e psicológicas favoráveis: administração de salários, plano de benefícios sociais, higiene e segurança do trabalho, recompensas, administração da disciplina, qualidade de vida no trabalho e estudo de clima organizacional); d) liderança e acompanhamento de pessoas (acompanhamento e controle das atividades para verificar resultados: bancos de dados, sistemas de informações gerenciais, auditoria de recursos humanos e trabalhista); e e) avaliação e reavaliação de processos, métodos e competências efetivas necessárias (procedimento cíclico de apreciação da conjuntura do desempenho de processos, métodos e competências em organizações, identificando as ações que precisam ser modificadas e aquelas que obtiveram êxito).

As abordagens da AOS de Moreira (2000), Ausubel (2003) e Antonello (2005) englobam: a) a aprendizagem como um processo, resultado ou produto; b) a ênfase em um ou vários níveis de análise de aprendizagem, englobando, ao mesmo tempo, o indivíduo, o grupo e as relações entre organizações / 
Rafaela Carolina da Silva, Miriam Fernandes Jesus, Vania Cristina Pastri Gutierrez, Regina Célia Baptista Belluzzo, Daniela Pereira Reis

Articulação entre a competência em informação, a gestão de pessoas e a aprendizagem organizacional significativa: uma reflexão sobre novas condutas aplicáveis às bibliotecas públicas

atitude favorável para aprender significativamente de forma reflexiva e crítica;

c) as abordagens descritivas, com foco nos processos da AOS; d) a aprendizagem prescritiva, com foco nos resultados da organização que aprende, por meio da informação e do conhecimento; e e) os processos de aprendizagem como uma mudança cognitiva e comportamental / conteúdo potencialmente significativo, envolvendo os princípios estabelecidos por Moreira (2000). Dito isso, foi efetuada a relação entre os padrões e indicadores de Colnfo da ALA/ACRL (2000) e de Belluzzo (2007), as abordagens de GP de Dutra (2004) e de Chiavenato (2008) e as abordagens da AOS, reflexiva e crítica de Moreira (2000), de Ausubel (2003) e de Antonello (2005), a fim de se estabelecer a articulação entre as três áreas e de compreender a relação da Colnfo, da AOS e da GP no auxílio à atuação profissional em BP. Os resultados são apresentados no Quadro 2.

\title{
Quadro 2 - Padrões da Colnfo, atuação profissional e resultados desejáveis em BP
}

\begin{abstract}
Padrão 1 - Compreensão da determinação da natureza e da extensão da necessidade de informação, relaciona-se à aplicação de pessoas a seus cargos e funções, por meio dos processos de aprendizagem como uma mudança cognitiva e comportamental, para o desenvolvimento de um conteúdo potencialmente significativo. Considera-se ser necessário que a pessoa reconheça as atividades que precisa desempenhar na organização, e que ela saiba qual é a sua necessidade de informação, além de como levantar recursos para suprir tal necessidade. Dessa forma, é necessário trabalhar com o conhecimento implícito dos bibliotecários, a fim de identificar abordagens cognitivas e comportamentais que auxiliarão na atuação profissional do indivíduo, assim como, aquelas que necessitam serem modificadas.
\end{abstract}

Síntese: O bibliotecário competente em informação em BP determina a natureza de seu acervo perante a extensão dos diferentes formatos de informação, conhecendo as diversas fontes de informação e conseguindo extrair a informação necessária. Já o usuário competente em informação em BP sabe lidar com a extensão dos diferentes formatos de informação, identificando e reconhecendo suas necessidades e interesses informacionais.

Padrão 2 - Acesso à informação necessária com efetividade. Está associado à aplicação de pessoas a seus cargos e funções, assim como com a perspectiva da aprendizagem como um processo, resultado ou produto. Cada pessoa tem uma habilidade específica, sendo que essa habilidade é necessária no reconhecimento de um problema da organização. Dessa maneira, ela precisa estar devidamente alocada para melhor desempenhar suas funções. 0 desempenho de funções é rotineiro e, portanto, o profissional aprende em uma educação permanente, já que reflete sobre as ações do seu dia a dia para melhorar os resultados e os produtos advindos de suas práticas profissionais.

Síntese: O bibliotecário competente em informação em BP promove, aos seus usuários, 0 acesso à informação necessária com efetividade, independentemente de sua plataforma e busca informações em outros lugares, não se restringindo ao seu acervo, bem como conhece e desenvolve esquemas de descrição e classificação com autoridade, a fim de 
Rafaela Carolina da Silva, Miriam Fernandes Jesus, Vania Cristina Pastri Gutierrez, Regina Célia Baptista Belluzzo, Daniela Pereira Reis

Articulação entre a competência em informação, a gestão de pessoas e a aprendizagem organizacional significativa: uma reflexão sobre novas condutas aplicáveis às bibliotecas públicas

\begin{abstract}
facilitar a recuperação da informação. O usuário competente em informação em BP acessa a informação com efetividade, independentemente de sua plataforma, conhecendo os sistemas de recuperação e as formas de inserir palavras-chave, assim como utilizando estratégias de busca, como operadores booleanos. Além do mais, esse usuário conhece as possibilidades de consultar o profissional da informação para obter as informações desejadas e a estrutura de suas informações, de modo a acessá-las e citá-las de forma correta.
\end{abstract}

Padrão 3 - Avaliação crítica da informação e das suas fontes, relativo à provisão de pessoas necessárias e adequadas e às abordagens descritivas, com foco nos processos da AOS. As pessoas devem ser alocadas para executarem as funções às quais têm maior familiaridade, experiência empírica, habilidades mentais, ou seja, maiores habilidades específicas, nunca deixando de reconhecer o todo da organização. A abordagem descritiva é um meio de capacitação das potencialidades das ações entre as pessoas, com ênfase nos processos de institucionalização, compartilhamento, mudança de comportamento e melhora no desempenho institucional, para que a organização seja vista como um sistema de informação.

Síntese: Tanto o bibliotecário quanto o usuário competente em informação em BP avaliam criticamente a informação que recebem, bem como sua fonte, possuindo capacidade de análise e síntese. Dito isso, realizam processos de significação e interpretação, estabelecendo parâmetros de avaliação das informações e fontes, identificando especificidades das autoridades e suas qualificações, da mesma maneira que contextualizam o novo conhecimento com os conhecimentos prévios sobre o tema, distinguindo sua utilidade para a resolução dos problemas.

Padrão 4 Uso da informação com efetividade para alcançar um objetivo ou obter um resultado, associando-se à manutenção de pessoas, dotando-as de competências e à aprendizagem prescritiva, com foco nos resultados da organização que aprende, por meio da informação e do conhecimento. Compreende-se a capacidade de escolha das informações relevantes a serem transformadas em conhecimento implícito ou as informações que serão compartilhadas, explicitamente. $\mathrm{O}$ auxílio no desenvolvimento dessa capacidade de acesso, tratamento, uso e compartilhamento da informação pode advir do aprendizado ao longo da vida, como ações prescritivas de práticas educativas.

Síntese: O bibliotecário competente em informação em BP busca direcionar o usuário para o uso da informação com efetividade, a fim de alcançar um resultado de articulação da informação com as regras de comunicação, em prol de disseminá-la. Do mesmo modo, usuários competentes em informação geram conhecimento reflexivo, tanto individualmente quanto em grupo, definindo o uso da informação de acordo com seus objetivos, reportandose aos autores das ideias utilizadas e, igualmente, estruturando o novo conhecimento a ser comunicado.

Padrão $\mathbf{5}$ - Compreensão das questões econômicas, legais e sociais da ambiência do uso da informação, concernente à liderança e ao acompanhamento de pessoas, com ênfase em um ou vários níveis de análise de aprendizagem, englobando, ao mesmo tempo, o indivíduo, o grupo e as relações entre organizações, para o desenvolvimento de atitudes favoráveis para aprender significativamente, em um processo de avaliação e reavaliação de processos, métodos e competências efetivas necessárias. Cabe tanto ao líder quanto aos demais colaboradores da instituição, compreender a organização como um todo, bem como o seu entorno, a fim de se empregar todos os níveis de AOS, para que os Padrões 1, 2, 3 e 4 possam se desenvolver como ferramentas estratégicas nos processos de gestão de pessoas, assim como nas relações entre as diferentes organizações em sociedade, trabalhando na resolução de problemas e na avaliação de procedimentos e estratégias organizacionais.

Síntese: O bibliotecário competente em informação em BP compreende as questões econômicas, legais e sociais da ambiência do uso da informação, adequando seus produtos e serviços às demandas culturais, de forma ética e legalmente. Igualmente, valoriza e estimula o uso de recursos de acesso livre, conscientizando e sensibilizando seu público 
Rafaela Carolina da Silva, Miriam Fernandes Jesus, Vania Cristina Pastri Gutierrez, Regina Célia Baptista Belluzzo, Daniela Pereira Reis

Articulação entre a competência em informação, a gestão de pessoas e a aprendizagem organizacional significativa: uma reflexão sobre novas condutas aplicáveis às bibliotecas públicas

sobre os danos e implicações da prática de plágio. Trabalha de acordo com as normas institucionais e as políticas de informações nacionais e internacionais, conhecendo e cumprindo com as legislações referentes ao direito do autor, do mesmo modo que promovem campanhas sobre a ética na pesquisa. Sob a mesma ótica, o usuário competente em informação acessa e usa a informação de forma ética e legalmente, utilizando fontes de informação que respeitem o direito do autor, identificando e rejeitando práticas de plágio. Dessa maneira, os usuários, na perspectiva do padrão 5 , cumprem com as regras estabelecidas na instituição, conhecendo seus direcionamentos e normativas, além de darem crédito aos autores utilizados em suas pesquisas.

Fonte: Elaborado pelas autoras.

Sendo assim, foi possível verificar que a inter-relação entre a Colnfo, a GP e AOS, institucionalizadas na BP, ocorre por meio de cinco capacidades: a) reconhecer as necessidades de informação (identificação das informações necessárias para a solução de problemas individuais/organizacionais); b) armazenar e recuperar informação (gestão eficiente da informação e uso inteligente de ferramentas tecnológicas, seleção, tratamento, disseminação, descarte e recuperação da informação para seu uso assertivo); c) aplicar a informação para criar e comunicar conhecimento (institucionalização da informação tratada no item anterior, com base nos conhecimentos implícitos e explícitos; ressalta-se que o conhecimento implícito, quando disseminado, torna-se explícito, por meio de fluxos de informação, normas e procedimentos implementados); d) fazer uso eficaz e ético da informação (utilizar a informação corretamente com base em uma postura ética e legal, seguindo normas sociais e legislação vigente); e e) localizar e avaliar a qualidade da informação (uso de fontes de informação seguras, avaliação da veracidade da informação e da sua qualidade no âmbito inovador, agregando-a e aplicando-a, de maneira estratégica, na performance informacional do usuário).

\section{CONSIDERAÇÕES FINAIS}

Considerando-se a complexidade da sociedade contemporânea, a Colnfo auxilia na escolha das informações relevantes para a compreensão das ações sociais, assim como para o compartilhamento de conhecimento entre indivíduos, o que permite maior segurança de atuação nos ambientes políticos, 
sociais, econômicos e educacionais dos contextos em que as práticas informacionais são necessárias. Portanto, essa competência pode ser vista como auxílio na escolha das informações relevantes em BP e que, posteriormente, serão compartilhadas em sociedade, à medida que a Colnfo passa a ser desenvolvida e disseminada para todos os públicos. A GP, em BP, deve ir ao encontro do desenvolvimento de processos que promovam, nos bibliotecários, a capacidade de reconhecer as necessidades de informação, armazenar e recuperar a informação, aplicar a informação para criar e comunicar conhecimento, fazer uso eficaz e ético da informação e localizar e avaliar a qualidade da informação. Quando essas capacidades são trabalhadas na GP, a AOS é produzida por meio de atividades de identificação das informações necessárias para a solução de problemas individuais/organizacionais; da gestão eficiente da informação e do uso inteligente de ferramentas tecnológicas, seleção, tratamento, disseminação, descarte e recuperação da informação; da institucionalização da informação, a partir de conhecimentos implícitos e explícitos; do uso correto da informação, com base em uma postura ética e legal, seguindo as normas sociais e a legislação vigente; e do uso de fontes de informação seguras, bem como da avaliação da veracidade da informação e da sua qualidade no âmbito inovador, agregando-a e aplicando-a, de maneira estratégica, na performance informacional do usuário.

Nesse cenário, acredita-se que a Colnfo pode ser considerada como uma ferramenta estratégica na GP para a AOS em BP, e na área da Ciência da Informação, uma vez que está alinhada ao papel dessas instituições, buscando integração das comunidades nas quais essas organizações estão inseridas, assim como a imersão dos indivíduos nos processos geradores de informação e de conhecimento visando à melhor compreensão de mundo e ao exercício da cidadania. Dessa maneira, ao trabalhar com a inter-relação das capacidades das três áreas destacadas por este estudo, os bibliotecários atuantes em BP serão capazes de democratizar o acesso à informação, capacitando os 
usuários para o seu uso crítico e reflexivo. Trata-se, portanto, de permitir a reflexão, a crítica e a construção de ideias, por meio do compartilhamento da informação e da geração de conhecimento em sociedade, estabelecendo, assim, uma interlocução com as esferas política, econômica, social, tecnológica e cultural. Dito isso, este estudo oferece discussão de ordem conceitual, por avançar na interseção a que propõe (Colnfo, GP e AOS), contribuindo com atuação dos temas abordados individualmente e quanto aos resultados. Com a aplicação dos aspectos tratados teoricamente nas práticas profissionais, pesquisa aplicada e outros exemplos, foi possível aferir que a perspectiva, em relação aos temas tratados, pode proporcionar resultados satisfatórios para as políticas relacionadas às $\mathrm{BP}$, bem como aos seus usuários apoiando-se na apropriação, transposição e aplicação de novas condutas de gestão, como requisitos necessários ao desenvolvimento dessas bibliotecas que devem se destacar por sua atuação. Logo, tal inter-relação é fundamental para tornar a BP em um espaço de diálogo e exercício da cidadania, além de configurá-la como um centro ativo de promoção cultural e educacional.

\section{REFERÊNCIAS}

AMERICAN LIBRARY ASSOCIATION. Presidential Committee on Information Literacy: final report. Chicago: ALA, 1989. Disponível em: http://www.ala.org/acr//publications/whitepapers/presidential. Acesso em: 08 set. 2018.

ANGELONI, M. T.; STEIL, A. V. Alinhamento de estratégias, aprendizagem e conhecimento organizacional. In: TARAPANOFF, K. Aprendizado organizacional: fundamentos e abordagens multidisciplinares. Curitiba: IBPEX, 2011. v. 1. p. 115-148.

ANTONELLO, C. S. A metamorfose da aprendizagem organizacional: uma revisão crítica. In: RUAS, R.; ANTONELLO, C. S.; BOFF, L. H. (Orgs.).

Aprendizagem organizacional e competências. Porto Alegre: Artmed, 2005. p. 12-33. 
Rafaela Carolina da Silva, Miriam Fernandes Jesus, Vania Cristina Pastri Gutierrez, Regina Célia Baptista Belluzzo, Daniela Pereira Reis

Articulação entre a competência em informação, a gestão de pessoas e a aprendizagem organizacional significativa: uma reflexão sobre novas condutas aplicáveis às bibliotecas públicas

ASSOCIATION OF COLLEGE AND RESEARCH LIBRARIES. Information literacy competency standards for higher education. Chicago: ALA/ACRL. 2000.

AUSUBEL, D. P. Aquisição e retenção de conhecimentos: uma perspectiva cognitiva. Lisboa: Plátano, 2003.

BARRETO, A. M.; PARADELLA, M. D.; ASSIS, S. Bibliotecas públicas e telecentros: ambientes democráticos e alternativos para a inclusão social. Ciência da Informação, Brasília, v. 37, n. 1, abr. 2008. Disponível em: http://www.scielo.br/scielo.php?script=sci_arttext\&pid=S0100$19652008000100003 \&$ Ing=en\&nrm=iso. Acesso em: 11 ago. 2018.

BELLUZZO, R. C. B. Competências e novas condutas de gestão: diferenciais de bibliotecas e sistemas de informação. In: VALENTIM, M. L. P. (Org.).

Ambientes e fluxos de informação. São Paulo: Cultura Acadêmica, 2010. p. 23-54.

BELLUZZO, R. C. B. Construção de mapas: desenvolvendo competências em informação e comunicação. 2. ed. Bauru: Cá entre nós, 2007.

BELLUZZO, R. C. B.; FERES, G. F. Competência em informação, criatividade e inovação: uma experiência didática sob o enfoque de redes de conhecimento nas organizações. In: CONGRESSO BRASILEIRO DE BIBLIOTECONOMIA, DOCUMENTAÇÃO E CIÊNCIA DA INFORMAÇÃO, 25., 2013. Anais [...]. Florianópolis: FEBAB; ACB, 2013. Disponível em:

https://portal.febab.org.br/anais/article/view/1512/1513. Acesso em: 18 set. 2018.

BELLUZZO, R.C.B.; KOBAYASHI, M. do C.; FERES, G. G. Information literacy: um indicador de competência para a formação permanente de professores na sociedade do conhecimento. Educação Temática Digital, Campinas, v. 6, n. 1, p. 81-99, dez. 2004.

BERNARDINO, M. C. R.; SUAIDEN, E. J. O papel social da biblioteca pública na interação entre informação e conhecimento no contexto da ciência da informação. Perspectivas em Ciência da Informação, v. 16, n. 4, p. 29-41, out./dez. 2011. Disponível em: http://www.scielo.br/pdf/pci/v16n4/v16n4a04.pdf. Acesso em: 17 ago. 2018.

CAMPELLO, B. Letramento informacional no Brasil: práticas educativas de bibliotecas escolares de ensino básico. Tese (Doutorado em Ciência da Informação) - Universidade Federal de Minas Gerais, Belo Horizonte, 2009. Disponível em: http://www.bibliotecadigital.ufmg.br/dspace/bitstream/handle/1843/ECID- 
Rafaela Carolina da Silva, Miriam Fernandes Jesus, Vania Cristina Pastri Gutierrez, Regina Célia Baptista Belluzzo, Daniela Pereira Reis

Articulação entre a competência em informação, a gestão de pessoas e a aprendizagem organizacional significativa: uma reflexão sobre novas condutas aplicáveis às bibliotecas públicas

7UUPJY/tesebernadetesantoscampello.pdf?sequence=1. Acesso em: 02 ago. 2017.

CAPRIOLI, K. C.; ARAÚJO, B. F. Von B. A relação entre o comprometimento afetivo e as dimensões da Aprendizagem Organizacional. Revista

Administração em Diálogo, São Paulo, v. 18, n. 3, p. 76-103, set./out./nov./dez. 2016. Disponível em:

https://revistas.pucsp.br/index.php/rad/article/view/21453/0. Acesso em: 10 set. 2018.

CATIVO, E. S. da S.; CATIVO, J.; SOUZA, A. J. de. Competências demandadas por bibliotecários na gestão de bibliotecas: uma revisão bibliográfica. In: CONGRESSO BRASILEIRO DE BIBLIOTECONOMIA, DOCUMENTAÇÃO E CIÊNCIA DA INFORMAÇÃO, 27., 2017, Fortaleza. Anais [...]. Fortaleza: FEBAB, 2017. Disponível em: https://portal.febab.org.br/anais/article/view/1800/1801. Acesso em: 09 set. 2019.

CATTS, R.; LAU, J. Towards information literacy indicators. Paris: UNESCO, 2008.

CAVALCANTE, L. E.; RASTELI, A. A competência em informação e o bibliotecário mediador da leitura em biblioteca pública. Encontros Bibli, Florianópolis, v. 18, n. 36, p. 157-180, 2013. Disponível em: https://periodicos.ufsc.br/index.php/eb/article/view/15182924.2013v18n36p157/24518. Acesso em: 02 jun. 2020.

CHIAVENATO, I. Comportamento organizacional: a dinâmica do sucesso das organizações. 2. ed. Rio de Janeiro: Elsevier, 2010.

CHIAVENATO, I. Gestão de pessoas: o novo papel dos recursos humanos nas organizações. 3. ed. Rio de Janeiro: Elsevier, 2008.

DE LUCCA, D. M.; FIALHO, F. A. P.; VITORINO, E. V. Competência em informação e aprendizagem ao longo da vida nas organizações que aprendem.

Revista Ibero-Americana de Ciência da Informação, v. 11, n. 3, 2018. Disponível em: http://periodicos.unb.br/index.php/RICl/article/view/10373. Acesso em: 06 set. 2019.

DUDZIAK, E. A. A information literacy e o papel educacional das

bibliotecas. 2001. 187f. Dissertação (Mestrado em Ciência da Informação e Documentação) - Escola de Comunicação e Artes da Universidade de São Paulo, São Paulo, 2001.

DUTRA, J. S. Competências: conceitos e instrumentos para a gestão de 
pessoas na empresa moderna. São Paulo: Atlas, 2004.

FISCHER, A. L.; DUTRA, J. S.; NAKATA, L. E.; RUAS, R. Absorção do conceito de competência em gestão de pessoas: a percepção dos profissionais e as orientações adotadas. In: DUTRA, J. S.; FLEURY, M. T. L.; RUAS, R. (Org). Competências: conceitos, métodos e experiências. São Paulo: Atlas, 2008. p. 31-50.

GIL, A. C. Como elaborar projetos de pesquisa. 4. ed. São Paulo: Atlas, 2008.

GOH, S. C.; RICHARDS, G. Benchmarking the learning capability of organisations. European Management Journal, Glasglow, v. 15, n. 5, p. 575583, 1997.

GOMES, H. F. A biblioteca pública e os domínios da memória, da mediação e da identidade social. Perspectivas em Ciência da Informação, v. 19, número especial, p. 151-163, out./dez. 2014. Disponível em:

http://portaldeperiodicos.eci.ufmg.br/index.php/pci/article/view/2264. Acesso em: 4 set. 2019.

GRAMIGNA, M. R. Modelo de competências e gestão de talentos. 2. ed. São Paulo: Pearson, 2007.

JANIUNAITE, B.; PETRAITE, M.; CIBULSKAS, G. Organizational Learning in profit and non-profit organizations: the perspective of innovative culture development. In: INTERNATIONAL CONFERENCE ON INTELLECTUAL CAPITAL, KNOWLEDGE MANAGEMENT \& ORGANIZATIONAL LEARNING, 8., 2011. Anais [...]. Bangkok: Bangkok University, 2011.

LE BOTERF, G. De la competence: essai sur un attracteur étrange. Paris: Les éditions d'organisations, 1995.

LESSA, B.; GOMES, H.F. A biblioteca pública como um empório de ideias: evidências do seu lugar na sociedade contemporânea. Informação \& Sociedade, João Pessoa, v. 27, n. 1, p. 35-46, jan./abr. 2017.

LOPEZ, S. P., PÉON, J. M. M., ORDÁS, C. J. V. Organization Learning as a determining factor in business performance. The Learning Organization, Grimstad, v. 12, n. 3. p. 227-244, 2005.

MENESES PLACERES, G. La evaluación en la alfabetización informacional en el contexto de la educación superior: aproximación teórica. Biblios, Tacna, n. 31 , p. 1-11, 2008. 
MOREIRA, M. A. Aprendizagem significativa crítica. 2000. p. 1-24.

Disponível em: https://www.if.ufrgs.br/ moreira/apsigcritport.pdf. Acesso em: 19 nov. 2018.

REZENDE, J. F. D. Sustentabilidade e gestão ambiental. Natal: Epifania, 2015.

SANTOS, C. A. dos. Competência em Informação na formação básica dos estudantes da educação profissional e tecnológica. 2017. 287f. Tese (Doutorado em Ciência da Informação) - Universidade Estadual Paulista, Faculdade de Filosofia e Ciências, Marília, 2017. Disponível em: https://repositorio.unesp.br/handle/11449/150036. Acesso em: 08 set. 2018. SANTOS, V. C. B. Competência em informação na construção da inteligência competitiva nas organizações: o caso da empresa Mizumo. 177f. 2014. Dissertação (Mestrado em Ciência da Informação) - Universidade Estadual Paulista, Faculdade de Filosofia e Ciências, Marília, 2014.

SCHON, D. A. Educando o profissional reflexivo: um novo design para o ensino e a aprendizagem. Porto Alegre: Artmed, 2000.

SENGE, P.M. A quinta disciplina. 3. ed. Rio de Janeiro: Best Seller, 2004.

VERSIANI, A. F.; FISCHER, A. L. A aprendizagem organizacional como um campo específico de conhecimento no cenário dos estudos organizacionais. Revista Economia e Gestão da PUC Minas, Belo Horizonte, v. 8, n. 18, p. 1131, 2008.

YAFUSHI, C. A. P. A competência em informação para a construção de conhecimento no processo decisório: estudo de caso na Duratex de Agudos (SP). 229f. 2015. Dissertação (Mestrado em Ciência da Informação) -

Universidade Estadual Paulista, Faculdade de Filosofia e Ciências, Marília, 2015.

\title{
RELATIONSHIP BETWEEN INFORMATION LITERACY, STAFF MANAGEMENT AND ORGANIZATIONAL LEARNING: A REFLECTION AROUND PUBLIC LIBRARIES
}

\begin{abstract}
Introduction: the librarians, when being information managers, can develop the information literacy understanding that each individual is able to create, acquire, and share the knowledge, which infers in economic and social values of the organization, as it appropriates of more competent professionals in the management and execution
\end{abstract}


Rafaela Carolina da Silva, Miriam Fernandes Jesus, Vania Cristina Pastri Gutierrez, Regina Célia Baptista Belluzzo, Daniela Pereira Reis

Articulação entre a competência em informação, a gestão de pessoas e a aprendizagem organizacional significativa: uma reflexão sobre novas condutas aplicáveis às bibliotecas públicas

of processes, and activities. It is understood that the information literacy in as part of the staff management, and of the organizational learning models. Objective: to understand the relationship between the information literacy, the staff management, as well as the organization learning to the professional performance in public libraries. Methodology: the research is bibliographic, and explanatory, using qualitative approach, and descriptive type. Results: the staff management in order to the development of the meaningful learning in public libraries has to work with different abilities, which includes: ability to recognize the information needs, to store and to retrieve information, to apply information to create and to communicate knowledge, to make effective and ethical use of information, and to locate and to evaluate the quality of the information. Conclusions: when working with the interdisciplinary abilities of the three areas approached by this study, the librarians which work in public libraries will be able to democratize the information access, empowering the users for their critical use, and making them citizens.

Descriptors: Information literacy. Staff management. Organizational learning. Public libraries.

\title{
RELACIÓN ENTRE ALFABETIZACIÓN INFORMACIONAL, GESTIÓN DEL PERSONAL Y APRENDIZAJE SIGNIFICATIVO: UNA REFLEXIÓN SOBRE LAS BIBLIOTECAS PÚBLICAS
}

\begin{abstract}
RESUMEN
Introducción: Los bibliotecarios, como gestores de la información, pueden desarrollar la alfabetización informacional al entender que cada individuo es capaz de crear, adquirir y compartir conocimiento, lo que infiere en valores económicos y sociales de la organización, a medida que ésta se apropia de profesionales más competentes en la gestión y ejecución de sus procesos y actividades. Se entiende que la alfabetización informacional es parte integrante de los modelos de gestión del personal y del aprendizaje organizacional. Objetivo: comprender la relación existente entre las variables alfabetización informacional, gestión del personal y el aprendizaje organizacional en el auxilio a la actuación profesional en bibliotecas públicas. Metodología: se trata de una investigación bibliográfica y explicativa, cuyo enfoque es cualitativo de tipo descriptivo. Resultados: la gestión del personal para el aprendizaje significativo en bibliotecas públicas debe enfocarse en el desarrollo de iniciativas organizacionales que promuevan diferentes capacidades, tales como: la capacidad de identificar las necesidades de información, de almacenar, recuperar la información para crear y comunicar conocimiento, de hacer uso eficaz y ético de la misma, así como localizar y evaluar su calidad. Conclusiones: al trabajar con las capacidades interdisciplinarias de las tres variables abordadas por este estudio, los bibliotecarios actuantes en bibliotecas públicas serán capaces de democratizar el acceso a la información, capacitando a los usuarios para su uso crítico, más allá de proporcionarles condiciones de ciudadanía.
\end{abstract}

Descriptores: Alfabetización informacional. Administración del personal. Aprendizaje 
Rafaela Carolina da Silva, Miriam Fernandes Jesus, Vania Cristina Pastri Gutierrez, Regina Célia Baptista Belluzzo, Daniela Pereira Reis

Articulação entre a competência em informação, a gestão de pessoas e a aprendizagem organizacional significativa: uma reflexão sobre novas condutas aplicáveis às bibliotecas públicas

organizacional. Bibliotecas públicas.

Recebido em: 08.10.2019

Aceito em: 09.06.2020 